\title{
Effects of AIDS-related disability on workforce participation and earned income in Botswana: A quasi-experimental evaluation*
}

\author{
Mansour Farahani ${ }^{1 \#}$, Danae Roumis ${ }^{1}$, Ajay Mahal ${ }^{2}$, Marionette Holmes ${ }^{3}$, Gillian Moalosi ${ }^{4}$, \\ Chris Molomo ${ }^{5}$, Richard Marlink ${ }^{1,6}$ \\ ${ }^{1}$ AIDS Initiative, Harvard School of Public Health, Boston, USA; ${ }^{*}$ Corresponding Author: mfarahan@hsph.harvard.edu \\ ${ }^{2}$ School of Public Health and Preventive Medicine, Monash University, Melbourne, Australia \\ ${ }^{3}$ Department of Economics, Spelman College, Atlanta, USA \\ ${ }^{4}$ Botswana Harvard Partnership, Gaborone, Botswana \\ ${ }^{5}$ National AIDS Coordinating Agency (NACA), Gaborone, Botswana \\ ${ }^{6}$ Elizabeth Glaser Pediatric AIDS Foundation, Los Angeles, USA
}

Received 10 January 2013; revised 17 February 2013; accepted 25 February 2013

\begin{abstract}
Background: Botswana is regarded as a leader of progressive HIVIAIDS policy, as the first country in sub-Saharan Africa to establish a free, national antiretroviral therapy program. In light of such programmatic successes, it is important to evaluate the potentially changing relationship of HIVIAIDS to the wellbeing of individuals, households, and institutions in the country. Methods: We evaluate the effects of HIV-related illness on absenteeism and earnings several years after the start of the national treatment program among a random sample of adults in Botswana using survey data from 3999 individuals aged 15 to 49 , using quasi-experimental methods. We compare absenteeism between individuals with and without HIV-related illness, using a propensity score matching approach. We then estimate the effect of HIV-related illness on earnings using a Heckman selection model to account for selection into the workforce. We stratify our analyses by sex. Results: Men and women with HIV-related illness were absent by about 5.2 and $\mathbf{3 . 3}$ additional days, respectively, in the month prior to the survey compared to matched controls, and earned approximately $38 \%$ and $43 \%$ less, respectively, in the month prior to the survey compared to those without HIV-related illness. Conclusions: HIV-related illness appears to increase absenteeism in this sample and dramatically reduce earnings. The findings suggest a need for policies that confer greater financial security
\end{abstract}

\footnotetext{
*Competing interests: all authors declare that they have no competing
} interests for this work. to individuals with HIVIAIDS in Botswana.

Keywords: HIVIAIDS; Botswana; Absenteeism; Earnings; Propensity Score Matching; Heckman Selection Model

\section{INTRODUCTION}

In Botswana, over 350 thousand people are estimated to be living with HIV/AIDS [1]. The vast majority of HIV cases in the country are among working aged adults between 15 and 49 , with a prevalence in this age group of $25 \%$ [2]. The potential for reduced labor productivity of individuals who make up the majority of the workforce in the country has implications for the economic wellbeing of their households as well as the growth of the economy in Botswana. Several studies have demonstrated the detrimental macroeconomic effects of AIDS in countries with a high prevalence [3-13]. A recent model estimates that the growth rate of the economy in Botswana will slow by up to $2 \%$ annually through 2021 , rendering it one-fifth smaller than it might have been in the absence of AIDS, even considering widespread antiretroviral therapy [8]. An estimated 40 thousand uninfected people in Botswana have been pulled into poverty due to the slow economic growth caused by the epidemic [13], reflecting similar results from other settings showing the effect of the epidemic on household economies [14-22]. The effects of the epidemic related to absenteeism, workforce participation, and earnings could therefore have both short- and long-term implications for the economy in Botswana.

In recognition of such far-reaching social and economic consequences of the epidemic, the Government of Botswana established a national antiretroviral therapy 
(ART) program in 2002, known as Masa or "new dawn" in Setswana, and began rapid scale-up across the country in 2004. The Masa program provides antiretroviral drugs, essential laboratory testing, and other care and treatment services free of charge to any individual who has tested positive for HIV and qualifies for treatment based on virologic or clinical criteria. The Masa program has a dual purpose to improve the length and quality of life for individuals with HIV and defray the enormous cost of life-long treatment, easing financial burdens on households and individuals.

Several years after the Masa program has been established and expanded nation-wide, research has shown dramatic reductions in HIV mortality rates and promising clinical outcomes among individuals enrolled in the program [23]. Important questions still remain to be answered regarding the financial well-being of individuals with HIV in the country. Therefore, two important factors motivate the evaluation of the indirect economic effects of HIV-related illness in Botswana. First, as HIV becomes more of a chronic condition and the life expectancy of those with HIV is greatly extended thanks to the successful scale up of treatment and care services, workforce participation and economic productivity may be affected to a greater degree by illness and disability rather than death [24]. Secondly, given that the national ART program is fully subsidized in Botswana, we assume that direct costs for care and treatment are of lesser concern in this context than indirect costs, such as earnings potentially foregone via absenteeism.

There is abundant evidence from developed countries linking HIV-related morbidity to increased absenteeism and reduced productivity and wages along a gradient of disease severity [25-37]. Only a small number of studies examine these effects in developing countries [38-42]. More often, studies conducted in the developing world demonstrate adverse economic effects of the epidemic at the household level, focusing mostly on expenditures for care and treatment rather than potential opportunity costs, and more frequently examine the effects of deaths due to HIV/AIDS rather than illness [7,8,12,14-22,39,43,44].

Our analysis therefore adds to the evidence base in terms of indirect economic impacts of HIV at the individual level in a developing country context. We use a random sample of adults from across the country, and rigorous quasi-experimental methods to evaluate the effects of HIV-related illness on absenteeism and earnings in Botswana, with special attention to differences between men and women.

\section{METHODS}

\subsection{Data}

We surveyed 1840 households containing 6480 individuals randomly selected in three urban and three rural sites across Botswana over three months in 2007. Overall HIV prevalence in these six locations ranges from 13.3\% to $26.5 \%$ [2]. One member of each household, most often the head of household, was asked to respond to the questionnaire and provide information for each household member. Informed consent was obtained from all respondents before the administration of the questionnaire, and ethical review committee approvals were acquired from the Harvard School of Public Health and the Botswana Ministry of Health before the survey.

We included 3999 individuals from 1768 households between the ages of 15 to 49 with complete information in our analysis, representing $62 \%$ of the individuals from our randomly selected population. Since the survey instrument was randomly administered to individuals in their home, sometimes in the presence of others in the household, it was not consistent with ethical human research practices to ask respondents directly about their HIV infection status. Instead, they were asked to list all episodes of illness within the last year and last month, and attribute a cause to each illness episode. The "HIVrelated illness" variable is therefore an indicator equal to 1 if an individual attributed any episode of illness in the past year or month to HIV through self-report, and 0 otherwise.

Outcomes of interest include absenteeism and earnings in the last month. Absenteeism was defined as the number of days last month that the individual was unable to perform normal activities, including any inpatient days. Absenteeism questions were asked uniformly for all episodes of illness for each member of every household surveyed. The comparison we make is therefore the number of days of absenteeism reported by those who attribute the illness episode to HIV, versus those who attribute it to any other cause. Earnings include all reported income from paid work, and these skewed data were transformed with the natural logarithm for the analysis. Our indicator of workforce participation is based on the earnings data, and is defined such that anyone who reported a positive amount of earnings in the past month was considered part of the workforce, while those reporting no earnings from paid work in the last month were considered not part of the workforce.

\subsection{Propensity Score Matching}

We apply a propensity score matching approach to compare self-reports of absenteeism in the last month between individuals reporting HIV-related illness and a group of matched controls [45-47]. Propensity score matching methods allow us to simulate "treatment" and "control" groups by matching on a few observed covariates, resulting in a quasi-randomized design that mimics the result of balance achieved by randomization $[46,48,49]$. We use three matching methods in order to 
validate the results, including nearest-neighbor, kernel, and radius matching $[45,50]$. Once individuals are matched, we can compare days of absenteeism between those who have reported HIV-related illness and those who have not. This is an estimate of the "average treatment effect on the treated" (ATT) of HIV-related illness. We stratified the analysis on sex, and patients in either group who are not matched are eliminated from the comparison. It is important to note that while propensity score methods can reduce bias due to observed differences between treatment groups, they are still subject to biases from unobserved differences.

\subsection{Heckman Selection Model}

We evaluate whether HIV-related illness has an impact on earnings using a Heckman selection model, which allows us to control for the fact that not all individuals enter the workforce. This conditional analysis is important because we cannot extrapolate the effect of HIVrelated illness on earnings that we observe among workers to non-workers since many of the unobservable characteristics that lead people to forego employment, e.g. worse health status, also lead them to less success once employed [51]. If people do self-select into the sample of workers, we may obtain biased estimates without properly adjusting for that phenomenon, as the combination of factors leading to entrance into the workforce would be similar to an omitted variable in the regression [52, 53].

The Heckman selection model addresses this potential bias by first estimating the probability of entering the workforce, as a function of a series of observable and measured covariates, using a probit regression. The degree to which there is selection in the sample based on workforce participation is estimated in a term that is entered into the main linear regression to evaluate earnings among those who participated in the workforce last month. In this model, if the correlation coefficient rho $(\rho)$ given in the model output is not equal to zero; we have evidence of sample selection, meaning that indeed the observed characteristics in the probit regression have influenced participation in the workforce [54]. In all of our analyses, we specify our use of survey data with enumeration areas as the primary sampling unit, and household weights as the sampling weights. We used STATA 11 software to carry out our analyses [55].

\section{RESULTS}

\subsection{Descriptive Statistics}

Sample characteristics and summary statistics are presented in Table 1, stratified by sex. The samples of men and women are similar in many ways. The average age is
Table 1. Sample characteristics and descriptive statistics.

\begin{tabular}{|c|c|c|c|c|c|c|}
\hline & \multicolumn{3}{|c|}{ Males } & \multicolumn{3}{|c|}{ Females } \\
\hline & Mean & SD & $\mathrm{n}$ & Mean & SD & $\mathrm{n}$ \\
\hline Age & 28.35 & 8.76 & 1802 & 28.77 & 8.93 & 2197 \\
\hline \multicolumn{7}{|l|}{ Education } \\
\hline No school & 0.06 & 0.23 & 1802 & 0.06 & 0.23 & 2197 \\
\hline Primary schooling & 0.14 & 0.35 & 1802 & 0.16 & 0.36 & 2197 \\
\hline Secondary schooling & 0.60 & 0.49 & 1802 & 0.63 & 0.48 & 2197 \\
\hline Tertiary Schooling & 0.20 & 0.40 & 1802 & 0.15 & 0.36 & 2197 \\
\hline $\begin{array}{l}\text { Married/Living } \\
\text { with partner }\end{array}$ & 0.24 & 0.43 & 1802 & 0.24 & 0.42 & 2197 \\
\hline Dependency Ratio & 0.33 & 0.45 & 1802 & 0.50 & 0.58 & 2197 \\
\hline \multicolumn{7}{|l|}{ Setting* } \\
\hline Rural & 0.72 & 0.45 & 1802 & 0.72 & 0.45 & 2197 \\
\hline Urban & 0.28 & 0.45 & 1802 & 0.28 & 0.45 & 2197 \\
\hline \multicolumn{7}{|l|}{ Wealth Quintiles } \\
\hline Quintile 1 (lowest) & 0.19 & 0.39 & 1802 & 0.22 & 0.41 & 2197 \\
\hline Quintile 2 & 0.20 & 0.40 & 1802 & 0.18 & 0.38 & 2197 \\
\hline Quintile 3 & 0.20 & 0.40 & 1802 & 0.21 & 0.41 & 2197 \\
\hline Quintile 4 & 0.20 & 0.40 & 1802 & 0.20 & 0.40 & 2197 \\
\hline Quintile 5 (highest) & 0.21 & 0.40 & 1802 & 0.19 & 0.39 & 2197 \\
\hline $\begin{array}{c}\text { Reported } \\
\text { HIV-related illness }\end{array}$ & 0.02 & 0.13 & 1802 & 0.02 & 0.13 & 2197 \\
\hline \multicolumn{7}{|l|}{ Outcome Variables } \\
\hline $\begin{array}{l}\text { Absentee days, } \\
\text { last month }\end{array}$ & 0.51 & 3.24 & 1802 & 0.54 & 3.13 & 2197 \\
\hline $\begin{array}{l}\text { Absentee days } \\
\text { if }>0 \text {, last month }\end{array}$ & 9.79 & 10.53 & 94 & 8.24 & 9.28 & 144 \\
\hline $\begin{array}{l}\text { Participated in } \\
\text { workforce, last month }\end{array}$ & 0.56 & 0.50 & 1802 & 0.45 & 0.50 & 2197 \\
\hline $\begin{array}{c}\text { Earnings of } \\
\text { workforce (Pula) }\end{array}$ & 2871 & 3323.11 & 1019 & 2194 & 3200.99 & 992 \\
\hline
\end{tabular}

*Urban includes Gaborone, Selebi-Phikwe, and Jwaneng; Rural includes Kanye, Ghanzi, and Hukuntsi; ${ }^{* *}$ Earnings rounded to the nearest Pula (7.7 Pula to the US dollar), only presented for those reporting a positive amount of earnings in the last month.

about 28 years old, and two-thirds of both male and female respondents have achieved secondary education. More men have achieved some form of higher education $(20 \%)$ compared to women (15\%). Women live in households with higher dependency ratios $(0.50)$ compared to men $(0.33)$. In our sample, $72 \%$ of individuals lived in rural areas, and $28 \%$ in urban areas. We also constructed a household wealth index using ownership of household assets in a principal component analysis [56], and partitioned this into five quintiles. Overall $19 \%$ of males and $22 \%$ of females fell into the lowest quintile, while $21 \%$ of males and $19 \%$ of females fell into the highest quintile. Approximately $2 \%$ of males and females 
alike reported HIV-related illness. The average age among individuals reporting HIV-related illness in the last year was 35\%, 57\% were female, $31 \%$ were married or living with a partner, $49 \%$ were residents of rural areas, $64 \%$ were educated at the secondary or tertiary level, and $66 \%$ fell into the lowest wealth quintile. In total across the whole sample, men and women reported an average of one half-day of absenteeism in the last month $(0.51$ and 0.54 respectively). However, excluding those who reported no absenteeism, men report on average 9.79 days and women report 8.24 days of absence in the last month. More men (56\%) participated in the workforce based on positive earnings data compared to women (45\%). Among these individuals, men made an average of about 2871 Pula (US \$372) in the last month, and women made an average of 2194 Pula (US \$284) in the last month.

\subsection{Outcomes}

Absenteeism: The results of the logistic regression (not shown) used to calculate the propensity scores indicate that the probability of reporting HIV-related illness in our sample rises with age at first and then declines. The peak age at which HIV-related illness is reported is 44 for men and 48 for women. Rural residents and people from a low socioeconomic status are more likely to report HIV-related illness than urban residents and individuals of middle and high socioeconomic status, respectively. Table 2 presents our findings from the propensity score matching comparisons. We report the average treatment effect on the treated (ATT), the average difference in absenteeism reported between persons reporting HIVrelated illness and their matched set of controls. Men reporting HIV-related illness are more likely to report longer periods of absenteeism in the previous month by

Table 2. Absenteeism due to HIV-related illness, propensity score matching.

\begin{tabular}{ccccc}
\hline & \multicolumn{2}{c}{$\begin{array}{c}\text { Difference in } \\
\text { absenteeism } \\
\text { (days last month) }\end{array}$} & $\begin{array}{c}\text { Observations } \\
\text { ("treated" } \\
\text { individuals) }\end{array}$ & $\begin{array}{c}\text { Observations } \\
\text { (matched } \\
\text { controls) }\end{array}$ \\
\hline $\begin{array}{c}\text { Males } \\
\text { Nearest-Neighbor }\end{array}$ & $5.24^{* * *}$ & $(1.93)$ & 30 & 1772 \\
Kernel & $5.22^{* *}$ & $(2.16)$ & 30 & 1772 \\
Radius & $5.24^{* * *}$ & $(1.93)$ & 30 & 1772 \\
Females & & & & \\
Nearest-Neighbor & $3.33^{* *}$ & $(1.41)$ & 40 & 2157 \\
Kernel & $3.32^{* * *}$ & $(0.95)$ & 40 & 2157 \\
Radius & $3.33^{* *}$ & $(1.41)$ & 40 & 2157 \\
\hline
\end{tabular}

Estimates represent the average treatment effect among the treated (ATT); Standard errors in parentheses, Kernel matching uses bootstrapped standard errors, all other methods use analytical standard errors, ${ }^{*} \mathrm{p}<0.10,{ }^{* *} \mathrm{p}<0.05$, $\mathrm{p}<0.01$. approximately 5.2 days, while women report about 3.3 additional days, compared to their matched controls.

Earnings: The results of the Heckman Selection Model are presented in Table 3. The first step in comparing earnings was controlling for self-selection into the workforce. The results of this step align with general expectations. HIV-related illness appears to have a negative effect on participation in the workforce for both sexes, and the effect is stronger and highly significant among females. Age is significant and positive for both sexes and the effect drops off at older ages as the age-squared term is negative and significant. Both men and women in rural areas appear to be less likely to par-

Table 3. Impact of HIV-related illness on Earnings, Heckman Selection Model (MLE).

\begin{tabular}{|c|c|c|c|c|}
\hline \multirow{2}{*}{$\begin{array}{c}\begin{array}{c}\text { Log of Earnings } \\
\text { (last month) }\end{array} \\
\text { HIV-related illness }\end{array}$} & \multicolumn{2}{|c|}{ Males } & \multicolumn{2}{|c|}{ Females } \\
\hline & $-0.47^{* * *}$ & $(0.17)$ & $-0.57^{* *}$ & $(0.24)$ \\
\hline Age & -0.02 & $(0.04)$ & $0.21^{* * *}$ & $(0.04)$ \\
\hline Age-squared & 0.0005 & $(0.0005)$ & $-0.002^{* * *}$ & $(0.0005)$ \\
\hline Rural & 0.04 & $(0.11)$ & -0.16 & $(0.17)$ \\
\hline Primary schooling & -0.11 & $(0.18)$ & -0.19 & $(0.26)$ \\
\hline Secondary schooling & $0.27^{*}$ & $(0.16)$ & $0.49^{*}$ & $(0.26)$ \\
\hline Tertiary schooling & $1.11^{* * *}$ & $(0.19)$ & $1.73^{* * *}$ & $(0.28)$ \\
\hline Constant & $7.55^{* * *}$ & $(0.72)$ & $1.77^{* * *}$ & $(0.58)$ \\
\hline \multicolumn{5}{|l|}{ Selection Equation } \\
\hline HIV-related illness & -0.39 & $(0.31)$ & $-0.65^{* * *}$ & $(0.22)$ \\
\hline Age & $0.37^{* *} *$ & $(0.03)$ & $0.34^{* * *}$ & $(0.03)$ \\
\hline Age-squared & $-0.005^{* * *}$ & $(0.0005)$ & $-0.004^{* * *}$ & $(0.0004)$ \\
\hline Rural & $-0.24^{*}$ & $(0.14)$ & -0.19 & $(0.18)$ \\
\hline Primary schooling & 0.09 & $(0.24)$ & -0.18 & $(0.20)$ \\
\hline Secondary schooling & 0.12 & $(0.22)$ & $0.39^{*}$ & $(0.21)$ \\
\hline Tertiary schooling & 0.21 & $(0.23)$ & $0.86^{* * *}$ & $(0.22)$ \\
\hline $\begin{array}{l}\text { Married/Living with } \\
\text { partner }\end{array}$ & $0.71^{* * *}$ & $(0.10)$ & $-0.29^{* * *}$ & $(0.09)$ \\
\hline Dependency ratio & $-0.41^{* * *}$ & $(0.10)$ & $-0.13^{* *}$ & $(0.06)$ \\
\hline Quintile 2 & 0.04 & $(0.12)$ & $-0.30^{* * *}$ & $(0.08)$ \\
\hline Quintile 3 & 0.16 & $(0.12)$ & $-0.27^{* * *}$ & $(0.09)$ \\
\hline Quintile 4 & 0.09 & $(0.14)$ & $-0.42^{* * *}$ & $(0.09)$ \\
\hline Quintile 5 & $0.38^{* * *}$ & $(0.14)$ & $-0.51^{* * *}$ & $(0.11)$ \\
\hline Constant & $-6.24^{* * *}$ & $(0.55)$ & $-6.12^{* * *}$ & $(0.47)$ \\
\hline \multicolumn{5}{|l|}{ Athrho } \\
\hline Constant & $-1.09^{* * *}$ & $(0.19)$ & $1.02^{* * *}$ & $(0.13)$ \\
\hline \multicolumn{5}{|l|}{ lnsigma } \\
\hline Constant & -0.09 & $(0.06)$ & 0.003 & $(0.05)$ \\
\hline Observations & 1802 & & 2197 & \\
\hline
\end{tabular}

Standard errors in parentheses; ${ }^{*} \mathrm{p}<0.10,{ }^{* *} \mathrm{p}<0.05,{ }^{* * *} \mathrm{p}<0.01$; The natural logarithm is used to transform the skewed earnings data. Earnings data includes all reports of positive amounts. 
ticipate in the workforce, though the effect is significant only among men. The positive sign of the education variables suggests that higher education is correlated with an increased probability of working. The effects of secondary education and tertiary education are stronger and significant among females. A larger dependency ratio in the household appears to discourage working, which is significant for both men and women but a much stronger effect among men. Among males, being married or living with a partner has a strong positive effect on workforce participation, but a negative and significant effect on women's workforce participation. Men in the highest wealth quintile are significantly more likely to work than those in the lowest, while the effect is reversed for women, who are much less likely to participate in the workforce in the highest quintile compared to the lowest.

In the main linear regression, we observe that the effect of HIV-related illness on earnings is negative and significant for both sexes. Since we used the natural logarithm to transform the skewed earnings data, we exponentiate the coefficients to quantify the actual effect [57]. The effect of HIV-related illness is an approximately $38 \%$ reduction in last month's earnings among men, and $43 \%$ reduction among women. Among males, it seems that earnings increase with age but the effect is not statistically significant. For women, age has a positive and significant effect on earnings until the age of 53. Primary education is not statistically different from "no schooling" with regard to earnings, while earnings increase with secondary and tertiary levels of education for both sexes. The education effects are stronger among women. Interaction terms between HIV-related illness, age, and education level were insignificant in the model.

\section{DISCUSSION}

We find that working age adults reporting HIV-related illness in Botswana are reporting greater amounts of absenteeism, and that HIV-related illness contributes to reduced earnings. In addition, we find that the difference in absenteeism between those with HIV-related illness and without is smaller among women than among men, but that HIV-related illness is associated with reduced earnings of almost half of the previous month's earnings for women, and reduced earnings of about one-third for men. Our findings are consistent with studies from both the developed and developing world showing that HIV morbidity is associated with reduced likelihood of workforce participation and earnings [33-38,40,42]. However, our findings differ slightly in magnitude compared with previous research.

Specifically, the findings from this study show rates of absenteeism similar or higher to the upper bound from previous studies, and reductions in earnings at least double that from other studies in sub-Saharan Africa. The rates in absenteeism observed in the present analysis are very similar to reports from other studies specific to individuals in the month before they began initiation of antiretroviral therapy (ART) $[38,40,42]$. Mahal et al. (2008) use propensity score matching to show that individuals with HIV report about 2 additional days of absenteeism in the last month, compared with those without HIV [41]. Data from employees of the Debswana Diamond mining firm in Botswana have been used to show that absenteeism among workers at the firm with HIV peaks at approximately 5 days in the month prior to antiretroviral treatment (ART) initiation, and these researchers found no difference in absenteeism between men and women [39].

Our study offers several advantages over previous research. The sample we use is a large, random sample of adults from across the country, rather than a convenience sample. We use rigorous quasi-experimental methods, and focus specifically on differences between men and women. The study also has some limitations. Interestingly, the results regarding absenteeism in this study are very similar to estimates from previous studies specific to individuals who have not yet initiated ART. Our measurement of HIV-related illness and absenteeism rely on self-reports. It is possible that some individuals may have been hesitant to reveal their HIV status, and attributed their illness episode to some other cause. However, if this occurred, the result would be an underestimation of the impact of HIV-related illness on absenteeism on earnings.

In addition, we expect individuals to be sick at two distinct periods throughout their disease progression: within one year before and after their initiation on antiretroviral treatment (ART), and later when the disease has progressed substantially. If we were to make the assumption, considering the widespread voluntary testing and counseling campaign in Botswana in past years, that a self-report of HIV-related illness means that the individual has been tested and knows their status, the rate of absenteeism we see in this analysis is surprisingly high, since we might have expected these individuals to have already enrolled in the Masa program and been initiated on ART if they were eligible for treatment. It is possible that individuals could have been tested and not initiated treatment because they were waiting to qualify by virologic or clinical criteria, but this degree of absenteeism suggests that many might be eligible if not already on treatment. It is also possible that these individuals are simply not adhering to their treatment regimen, or that they have been on treatment for longer periods of time and are reaching later phases of disease progression. A limitation of this study is the inability to capture this element of treatment status, duration, and adherence among individuals in the sample. 
Stigma may play a role in the results we observe. Discrimination from employers could account for part of the difference in workforce participation and earnings observed among those reporting HIV-related illness. Without an indicator for stigma or discrimination that may have influenced employment or earnings, we could not distinguish whether individuals who did not report any earnings in the last month had been seeking work or were denied employment for any reason related to their illness. Enterprises may refrain from hiring HIV positive workers for various reasons including loss of investment in training, increased costs related to health, or reduced productivity, despite the increase in lifespan afforded by effective treatment. However, unpublished work using data from Botswana National ART Program database suggests that individuals often present late into the course of their disease for testing and treatment [58]. This suggests some delay with respect to testing or enrolling in treatment, which may explain some of the high reports of absenteeism in our data.

\section{RECOMMENDATIONS}

Our findings suggest at least two clear avenues for further research. It would be useful to continue this analysis over time in Botswana using a random sample from the adult population, as well as measure the enrollment of respondents in the Masa program, since our cross-sectional data does not allow us to make conclusions about trends in absenteeism or earnings over time and control for participation in the national program. Additionally, if absenteeism and earnings are impacted by HIV-related illness, which is of increasing importance as HIV becomes a chronic rather than terminal condition, effects on household coping mechanisms should be studied more intensively. Individuals or households that manage small enterprises, especially those engaged in the informal sector, may bear a heavier burden if the person with HIV or AIDS is the key worker. Some households may borrow, or receive cash or in-kind donations from other households while others may pull children out of school in order for them to work to bring in needed income. Other individuals in the household may be compelled to contribute, either taking up longer work hours or additional household responsibilities [18]. This information would have important implications for the types of policies and interventions that would be designed to ease financial shocks among these households.

\section{CONCLUSION}

Our findings indicate that HIV-related illness increases absenteeism among working age adults in Botswana, and reduces their earning potential. We find substantial differences in these effects between men and women. Our research is the first to our knowledge highlighting the high level of HIV-related absenteeism and reduced earnings using a random sample of the adult population, and rigorous quasi-experimental methods. These results have potential implications for employer practices such as granting paid sick leave, as well as government policies surrounding welfare and disability grants to people living with HIV or AIDS in Botswana. It also may indicate that individuals who present late into the course of their disease for testing and treatment are dramatically and negatively impacting their prospects for continued employment. Botswana spends more than any country per capita on HIV, an amount totaling about 70 million USD annually [59], and the Masa program represents the most extensive of its kind relative to need [8]. While this program protects against short-term catastrophic spending, the length of AIDS illness demands that attention be paid to the indirect consequences such as loss of earnings as they relate to the wellbeing of individuals supported by working aged adults, as well as the country's labor market.

\section{AUTHOR CONTRIBUTIONS}

$\mathrm{RM}$ and $\mathrm{AM}$ led the conceptualization and design of the study, with the assistance of MH, GM and CM. MF and DR carried out the analyses and interpretation of the data. MF and DR wrote the first draft of the manuscript. $\mathrm{RM}, \mathrm{AM}, \mathrm{MH}, \mathrm{GM}$ and $\mathrm{CM}$ assisted in editing and revising the manuscript. All authors have approved of the final version of the manuscript.

\section{ACKNOWLEDGEMENTS}

This research was supported by the Global Infectious Diseases (GID) Program's AIDS Innovative Research Fund at the Harvard Initiative for Global Health.

\section{REFERENCES}

[1] UNAIDS (2010) Progress Report of the National Response to the 2001 Declaration of Commitment on HIV and AIDS, Botswana Country Report.

[2] CSO (2009) 2008 Botswana AIDS impact survey III (BAIS III). Central Statistics Office, Government of Botswana.

[3] Cuddington, J.T. (1993) Modeling the macroeconomic effects of AIDS, with an application to Tanzania. World Bank Econ Rev, 7, 173-189. doi:10.1093/wber/7.2.173

[4] Bonnel, R. (2000) HIV/AIDS and economic growth: A global perspective. South African Journal of Economics, 68, 360-379. doi:10.1111/j.1813-6982.2000.tb01282.x

[5] Cuddington, J.T. and Hancock, J.D. (1994) Assessing the impact of AIDS on the growth path of the Malawian economy. Journal of Development Economics, 43, 363-368. doi:10.1016/0304-3878(94)90013-2 
[6] Arndt, C. and Lewis, J.D. (2000) The macro implications of HIV/AIDS in South Africa: A preliminary assessment. South African Journal of Economics, 68, 380-392. doi:10.1111/j.1813-6982.2000.tb01283.x

[7] MacFarlan, M. and Sgherri, S. (2001) The macroeconomic impact of HIV/AIDS in Botswana. In press.

[8] Jefferis, K., Kinghorn, A., Siphambe, H. and Thurlow, J. (2008) Macroeconomic and household-level impacts of HIV/AIDS in Botswana. AIDS, 22, S113-S119. doi:10.1097/01.aids.0000327631.08093.66

[9] Lisk, F. (2002) Labour market and employment implications of HIV/AIDS. Working Paper 1: International Labor Organization (ILO) Programme on HIV/AIDS and the World of Work, Geneva.

[10] Kgathi, D.L., Ngwenya, B.N. and Wilk, J. (2007) Shocks and rural livelihoods in the Okavango Delta, Botswana. Development Southern Africa, 24, 289-308. doi: $10.1080 / 03768350701327186$

[11] Greener, R. (2002) AIDS and macroeconomic impact. Working Paper, International AIDS Economics Network.

[12] Greener, R., Jefferis, K. and Siphambe, H. (2000) The impact of HIV/AIDS on poverty and inequality in Botswana. South African Journal of Economics, 68, 393-404. doi:10.1111/j.1813-6982.2000.tb01284.x

[13] Thurlow, J. (2007) Is HIV/AIDS undermining Botswana's "success story"? IFPRI Discussion Paper 00697, Washington DC.

[14] Bachmann, M.O. and Booysen, F.L.R. (2004) Relationships between HIV/AIDS, income and expenditure over time in deprived South African households. AIDS Care: Psychological and Socio-Medical Aspects of AIDS/HIV, 16, 817-826.

[15] Bachmann, M.O. and Booysen, F.L.R. (2006) Economic causes and effects of AIDS in South African households. AIDS, 20, 1861-1867. doi:10.1097/01.aids.0000244205.03382.84

[16] Bachmann, M.O. and Booysen, F.L.R. (2003) Health and economic impact of HIV/AIDS on South African households: A cohort study. BMC Public Health, 3, 8. doi:10.1186/1471-2458-3-8

[17] Duraisamy, P., Ganesh, A.K., Homan, R., Kumarasamy, N., Castle, C., Sripriya, P., et al. (2006) Costs and financial burden of care and support services to PLHA and households in South India. AIDS Care: Psychological and Socio-Medical Aspects of AIDS/HIV, 18, 121-127. doi:10.1080/09540120500159359

[18] Naidu, V. and Harris, G. (2005) The impact of HIV/AIDS morbidity and mortality on households - A review of household studies. South African Journal of Economics, 73, 533-544. doi:10.1111/j.1813-6982.2005.00037.x

[19] Russell, S. (2004) The economic burden of illness for households in developing countries: A review of studies focusing on malaria, tuberculosis, and human immunodeficiency virus/acquired immunodeficiency syndrome. American Journal of Tropical Medicine and Hygiene, 71, 147155.

[20] Tekola, F., Reniers, G., Mariam, D.H., Araya, T. and Davey, G. (2008) The economic impact of HIV/AIDS morbidity and mortality on households in Addis Ababa, Ethiopia. AIDS Care: Psychological and Socio-Medical Aspects of AIDS/HIV, 20, 995-1001. doi: $10.1080 / 09540120701777256$

[21] Wyss, K., Hutton, G. and N'Diekhor, Y. (2004) Costs attributable to AIDS at household level in Chad. AIDS Care-Psychological and Socio-Medical Aspects of AIDS/ $H I V, 16,808-816$. doi:10.1080/09540120412331290167

[22] Rajaraman, D., Russell, S. and Heymann, J. (2006) HIV/ AIDS, income loss and economic survival in Botswana. AIDS Care: Psychological and Socio-Medical Aspects of AIDS/HIV, 18, 656-662. doi:10.1080/09540120500287010

[23] Bussmann, H., Wester, C.W., Ndwapi, N., Grundmann, N., Gaolathe, T., Puvimanasinghe, J., et al. (2008) Five-year outcomes of initial patients treated in Botswana's National Antiretroviral Treatment Program. AIDS, 22, 23032311. doi:10.1097/QAD.0b013e3283129db0

[24] Nixon, S., Hanass-Hancock, J., Whiteside, A. and Barnett, T. (2011) The increasing chronicity of HIV in sub-Saharan Africa: Re-thinking "HIV as a long-wave event" in the era of widespread access to ART. Globalization and Health, 7, 41. doi:10.1186/1744-8603-7-41

[25] Oliva, J. (2009) Labour participation of people living with HIV/AIDS in Spain. Health Economics, 19, 491-500. doi: $10.1002 /$ hec. 1487

[26] Dray-Spira, R., Lert, F., Marimoutou, C., Bouhnik, A.-D. and Obadia, Y. (2003) Socio-economic conditions, health status and employment among persons living with HIV/ AIDS in France in 2001. AIDS Care: Psychological and Socio-Medical Aspects of AIDS/HIV, 15, 739-748. doi:10.1080/09540120310001618595

[27] Dray-Spira, R., Persoz, A., Boufassa, F., Gueguen, A., Lert, F., Allegre, T., et al. (2006) Employment loss following HIV infection in the era of highly active antiretroviral therapies. European Journal of Public Health, 16, 89-95. doi:10.1093/eurpub/cki153

[28] Ezzy, D., De Visser, R. and Bartos, M. (1999) Poverty, disease progression and employment among people living with HIV/AIDS in Australia. AIDS Care: Psychological and Socio-Medical Aspects of AIDS/HIV, 11, 405-414. doi:10.1080/09540129947785

[29] Massagli, M.P., Weissman, J.S., Seage 3rd, G.R. and Epstein, A.M. (1994) Correlates of employment after AIDS diagnosis in the Boston health study. American Journal of Public Health, 84, 1976-1981. doi:10.2105/AJPH.84.12.1976

[30] Rabkin, J.G., McElhiney, M., Ferrando, S.J., Van Gorp, W. and Lin, S.H. (2004) Predictors of employment of men with HIV/AIDS: A longitudinal study. Psychosomatic Medicine, 66, 72-78. doi:10.1097/01.PSY.0000108083.43147.6D

[31] Yelin, E.H., Greenblatt, R.M., Hollander, H. and McMaster, J.R. (1991) The impact of HIV-related illness on employment. American Journal of Public Health, 81, 79-84. doi:10.2105/AJPH.81.1.79

[32] Auld, M.C. (2002) Disentangling the effects of morbidity and life expectancy on labor market outcomes. Health Economics, 11, 471-483. doi:10.1002/hec.753

[33] Leigh, J.P., Lubeck, D.P., Farnham, P. and Fries, J.F. 
(1995) Potential and actual workdays lost among patients with HIV. Journal of Acquired Immune Deficiency Syndromes and Human Retrovirology, 8, 392-398. doi:10.1097/00042560-199504000-00011

[34] Scitovsky, A.A. and Rice, D.P. (1987) Estimates of the direct and indirect costs of acquired immunodeficiency syndrome in the United States, 1985, 1986, and 1991. Public Health Reports, 102, 5-17.

[35] Mullins, C.D., Whitelaw, G., Cooke, J.L. and Beck, E.J. (2000) Indirect cost of HIV infection in England. Clinical Therapeutics, 22, 1333-1345. doi:10.1016/S0149-2918(00)83030-1

[36] Oliva, J., Roa, C. and Llano, J. (2003) Indirect costs in ambulatory patients with HIV/AIDS in Spain: A pilot study. Pharmacoeconomics, 21, 1113-1121. doi:10.2165/00019053-200321150-00005

[37] Kass, N.E., Munoz, A., Chen, B., Zucconi, S.L. and Bing, E.G. (1994) Changes in employment, insurance, and income in relation to HIV status and disease progression. The multicenter AIDS cohort study. Journal of Acquired Immune Deficiency Syndromes, 7, 86-91.

[38] Fox, M.P., Rosen, S., MacLeod, W.B., Wasunna, M., Bii, M., Foglia, G., et al. (2004) The impact of HIV/AIDS on labour productivity in Kenya. Tropical Medicine \& International Health, 9, 318-324. doi:10.1111/j.1365-3156.2004.01207.x

[39] Habyarimana, J., Mbakile, B. and Pop-Eleches, C. (2010) The impact of HIV/AIDS and ARV treatment on worker absenteeism. Journal of Human Resources, 45, 809-839. doi:10.1353/jhr.2010.0032

[40] Larson, B.A., Fox, M.P., Rosen, S., Bii, M., Sigei, C., Shaffer, D., et al. (2008) Early effects of antiretroviral therapy on work performance: Preliminary results from a cohort study of Kenyan agricultural workers. AIDS, 22, 421-425. doi:10.1097/QAD.0b013e3282f3cc0c

[41] Mahal, A., Canning, D., Odumosu, K. and Okonkwo, P. (2008) Assessing the economic impact of HIV/AIDS on Nigerian households: A propensity score matching approach. AIDS, 22, S95-S101.

doi:10.1097/01.aids.0000327629.62350.59

[42] Rosen, S., Ketlhapile, M., Sanne, I. and Desilva, M.B. (2008) Differences in normal activities, job performance and symptom prevalence between patients not yet on antiretroviral therapy and patients initiating therapy in South Africa. AIDS, 22, S131-S139.

[43] Riviello, E.D., Sterling, T.R., Shepherd, B., Fantan, T. and Makhema, J. (2007) HIV in the workplace in Botswana: Incidence, prevalence, and disease severity. AIDS Research and Human Retroviruses, 23, 1453-1460. doi:10.1089/aid.2007.0132

[44] Canning, D., Mahal, A., Odumosu, O. and Okonkwo, P. (2006) The impact of HIV/AIDS on Nigerian households. In: Adeyi, O., Kanki, P., Odutolu, O. and Idoko, J., Eds., AIDS in Nigeria: Harvard Center for Population and De- velopment Studies, Harvard University Press, Cambridge, 193-212.

[45] Dehejia, R.H. and Wahba, S. (2002) Propensity scorematching methods for nonexperimental causal studies. Review of Economics and Statistics, 84, 151-161. doi:10.1162/003465302317331982

[46] Rosenbaum, P.R. and Rubin, D.B. (1983) The central role of the propensity score in observational studies for causal effects. Biometrika, 70, 41-55. doi:10.1093/biomet/70.1.41

[47] Guo, S. and Fraser, M.W. (2009) Propensity score analysis: Statistical methods and applications. Sage Publications, Thousand Oaks.

[48] Rubin, D.B. (1979) Using multivariate matched sampling and regression adjustment to control bias in observational studies. Journal of the American Statistical Association, 74, 318-328. doi:10.2307/2286330

[49] Rubin, D.B. (2006) Matched sampling for causal effects. New York Cambridge University Press, Cambridge. doi:10.1017/CBO9780511810725

[50] Heckman, J.J., Ichimura, H. and Todd, P. (1998) Matching as an econometric evaluation estimator. Review of Economic Studies, 65 261-294. doi:10.1111/1467-937X.00044

[51] Gronau, R. (1974) Wage comparisons-A selectivity bias. The Journal of Political Economy, 82, 1119-1143. doi:10.1086/260267

[52] Wooldridge, J.M. (2002) Econometric analysis of cross section and panel data. MIT Press, Cambridge.

[53] Heckman, J.J. (1979) sample selection bias as a specification error. Econometrica, 47, 153-161. doi: $10.2307 / 1912352$

[54] Cameron, A.C. and Trivedi, P.K. (2005) Microeconometrics: Methods and applications. Cambridge University Press, Cambridge. doi:10.1017/CBO9780511811241

[55] Becker, S.O. (2002) Estimation of average treatment effects based on propensity scores. Stata Journal, 2, 358377.

[56] Filmer, D. and Pritchett, L.H. (2001) Estimating wealth effects without expenditure data or tears: An application to educational enrollments in states of India. Demography, 38, 115-132

[57] Wooldridge, J.M. (2008) Introductory econometrics: A modern approach. South-Western College Publishing, Cincinnati.

[58] Farahani, M., Tilahun, H. and Marlink, R. (2010) Sevenyear mortality outcomes of the Botswana national HIV/ AIDS treatment program. Unpublished Report.

[59] UNAIDS (2008) Epidemiological fact sheet on HIV and AIDS: Core data on epidemiology and response. Botswana: UNAIDS, WHO Working Group on Global HIV/ AIDS and STI Surveillance. 